\title{
(50-400) MPa Aralığında İzlenebilir Dinamik Basınç Ölçümleri
}

\author{
${ }^{1}$ Yasin Durgut, ${ }^{* 2}$ Recep Yılmaz, ${ }^{3}$ Abdullah Hamarat, ${ }^{4}$ İlker Meral, ${ }^{5}$ Uğur Uslukılıç \\ 1,*2,3,4 Tübitak UME, Ulusal Metroloji Enstitüsü, Gebze-Kocaeli, Türkiye \\ ${ }^{4}$ KAL-MET Kalibrasyon Laboratuvarları, Bursa, Turkey
}

\section{Özet}

Dinamik basınç uygulamaları, son yıllarda endüstriyel gelişmeler paralelinde birçok alanda farklı uygulamalara sahne olmaktadır. Bu tip uygulamalarda uygulanan basınç statik olmayıp zamanla değişen bir basınç olduğundan, dinamik basınç olarak adlandırılmaktadır. Bu tip sistemlerde yapılan çalışmalarda, basıncın dinamik olarak çok küçük zaman birimlerindeki değişiminin ve davranışının ortaya konulması gerekmektedir. Dinamik basınç sistemlerinde yapılan ölçümlerde, dinamik kalibrasyon ölçüm zinciri olarak adlandırabileceğimiz bir ölçüm düzeneği mevcut olup bu düzenek başlıca, dinamik basınç sensörü, sinyal şartlandırıcı ve yükselteci ile veri toplama birimlerinden oluşmaktadır. Bu çalışmada, dinamik basınç sensörlerinin kalibrasyonlarında kullanılmak üzere, serbest düşme prensibine göre çalışan dinamik referans basınç standardı geliştirilmesi konusunda gerçekleştirilen çalışmayla ilgili bilgiler verilmiştir.

Anahtar Kelimeler: Dinamik, basınç, kalibrasyon, dinamik sensör, kütle düşürmesli sistem

\begin{abstract}
In the parallel to development in industry, development in dynamic pressure applications have been increased in recent years. In dynamic pressure applications, it is called dynamic pressure since the applied pressure is not static but changes over time. In the studies carried out in such systems, it is necessary to demonstrate the change and behaviour of pressure dynamically in very small time units. In the measurement of dynamic pressure systems, there is a measurement mechanism which can be called a dynamic calibration measurement chain which consists of a dynamic pressure sensor, signal conditioner and amplifier and data collection units. In this study, information is given about the development of dynamic reference pressure standard which works according to the free fall principle to be used in the calibration of dynamic pressure sensors.
\end{abstract}

Keywords: Dynamic, pressure, calibration, dynamic, sensor, drop mass system

*Sorumlu Yazar: Adres: Tübitak UME, Ulusal Metroloji Enstitüsü, Gebze-Kocaeli, Türkiye. E-mail adres: yilmaz.recep@tubitak.gov.tr, Telefon: +902626795000 


\section{Giriş}

Kalibrasyon, belirli koşullarda, ilk aşamada ölçüm standartları tarafından sağlanan büyüklük değerleri ve ölçüm belirsizlikleri ile bunlara karşılık gelen gösterge değerleri ve ilgili ölçüm belirsizlikleri arasında bir ilişkinin oluşturulduğu, ikinci aşamada ise bu bilginin ölçüm sonucunun göstergeden elde edilmesinde kullanıldığı işlemler dizisidir [1]. Ölçümde kullanılan tüm cihazların kalibre edilmiş olması ölçüm sonucunun doğruluğunun bilinmesi açısından olmazsa olmaz bir durumdur. Endüstride havacılık, otomotiv, balistik ölçümler, gıdaların işlenmesi [2, 3] gibi bazı alanlar vardır ki bu alanlarda yapılan basınç ölçümleri, statik ölçümler değillerdir. Ölçülen değerler zamana bağlı olarak değişiklik gösteren bir büyüklüğe sahiptirler. Bu şekildeki ölçümler "dinamik" ölçümler olarak tanımlanmaktadır. Dinamik basınç ölçümleri de tarif edilen bu sınıfa girer ve yapılan bir dinamik basınç kalibrasyonunda ölçülen değer kısa zaman aralığında kayda değer değişiklik gösterir. Bir basınç sensörünün dinamik kalibrasyonu ya da dinamik basınç ölçümü, kalibrasyonu yapılan sensörün dinamik davranışının, sensörün kullanılacağı yerdeki ihtiyaç duyulan ölçüm doğruluğuna uygun şekilde dinamik davranışının ortaya konulmasını ve analizini içermektedir. Dinamik basınç kalibrasyonunda, referans dinamik basınç standardı tarafından kalibrasyonu yapılacak sensöre uygulanmak üzere değeri zamanla değişen güvenilir, kontrol edilebilir ve değeri iyi bilinen dinamik basınç üretilmelidir. Üretilen dinamik basınç değeri, test sensörü de denilen kalibre edilecek dinamik basınç sensörü için referans basınç değeri olarak kullanılmak üzere sensöre uygulanarak sensörün ürettiği basınç ya da elektriksel yük tepkisi ölçülmektedir.

\section{Birincil Seviye Dinamik Kalibrasyon Standardı Tasarımı ve Çalışma Prensibi}

TUBITAK UME Ulusal Metroloji Enstitüsü, dinamik basınç sensörlerinin kalibrasyonarında referans standart olarak kullanılmak üzere, primer dinamik basınç standardı geliştirmektedir. Primer standart, bilinen en yüksek metrolojik seviyede üretilen ve ürettiği değerlerin başka bir referans tarafından doğrulanmasına gerek olmadan doğru referans değer olarak kabul edildiği referans cihazlardır [4]. Ayrıca Primer standart, birincil seviye ölçüm standardı olarak da adlandırılır. Birincil seviye ölçüm standardı, bir birincil seviye referans ölçüm prosedürü kullanılarak ya da özel olarak üretilen bir nesnenin özelliklerine dayanarak, genel kabul ile belirlenmiş ölçüm standardı olarak tanımlanır [1]. Tasarımı ve üretimi yapılan bu birincil standart serbest düşen kütle prensibi ile çalışmaktadır. Sistemin en önemli birimlerinden biri olarak tanımlanabilecek ölçüm başlığı birimi temel bileşenleri Şekil 1.'de verilmiştir. Ölçüm başlığı olarak adlandırılan ve $0,5 \mathrm{~cm}^{3}$ hacim değerine sahip olan kapalı hacime test edilecek sensörler ve piston-silindir ünitesi bağlanmaktadır. Hacim içine metrolojik özellikleri bilinen akışkan bir yağ basınç iletim ortamını teşkil etmesi amacıyla doldurulmaktadır. Klavuz miller üzerine yataklanmış kütle elektromıktanıs yardımıyla istenilen yüksekliğe çıkarılarak yukarıdan aşağı serbest düşme şeklinde bir hareket yaparak pistonun üzerine aniden çarpmaktadır. Kütle düşürmeli sistem, serbest düşme sırasında serbest düşen kütlenin kazandığı hareket enerjisini, pistonun üzerine düşmek suretiyle pistona ve oradan da basınç iletim sıvısı yardımıyla test edilecek sensörlere aktarmaktadır. 


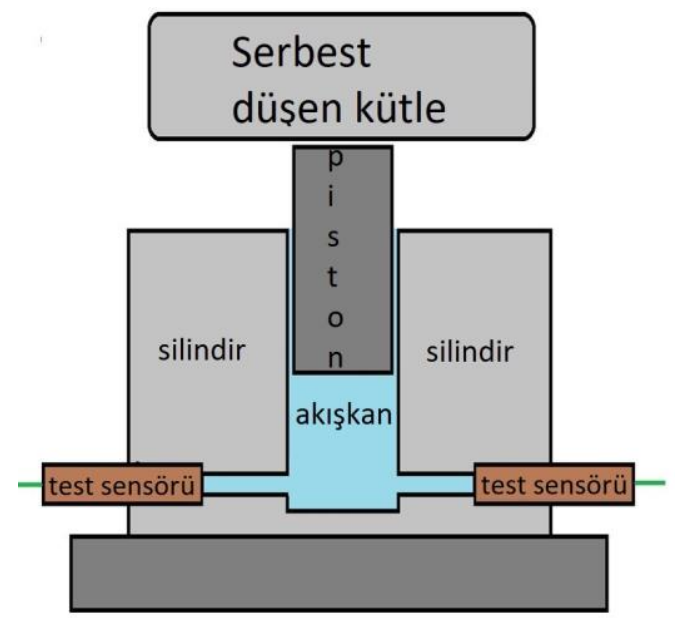

Şekil 1. Kütle düşürmeli sisteminin temel elemanları

Dinamik basınç kalibrasyon standardı genel görünümü Şekil 2.'de verilmiştir. Bu sistem dinamik basınç ölçer sensörlerin kalibrasyonlarında kullanılmak üzere anlık darbe sinyalleri üretmek amacıyla kullanılmaktadır. Bu şekildeki bir kalibrasyonda kullanılan akışkanın cinsine bağlı olmak koşuluyla test sensörleri çıkışları yaklaşık (3-5) milisaniye genişliğinde yarı sinüs bir şekle sahip bir gerilim sinyali olmaktadır. Geliştirilen makinada oluşturulacak dinamik basıncın \%1,5 belirsizlikle $10 \mathrm{MPa}$ ile $500 \mathrm{MPa}$ basınç değerleri arasında olması hedeflenmektedir. Dinamik basınç kalibrasyon sistemi, mekanik kütle düşürmeli sistem, ölçüm başlığı, laser interferometre sistemi ve test sensörü ve ona ait yükselteç bölümlerinden oluşmaktadır. Serbest düşen kütle yaklaşık 8,8 kilogram ağırlığındadır. İnterferometre lazer başlıkları gövdeye sabitlenmiş ve lazer ışı̆̆ının yansıtıldığı retroreflektör, hareketli serbest düşen kütle üzerine sabitlenmiştir. İnterferometre serbest düşen kütlenin zamana karşı konum bilgisini ölçmekte ve buna bağlı veri toplama sistemi de düşen kütlenin ivmesini hesaplamaktadır. Bu bilgiler ışı̆̆ında lazer tabanlı veri toplama sisteminin oluşturduğu net basınç toplam elde edilen kuvvetin pistonun alan değerine bölünmesiyle elde edilir. Serbest düşen kütle istenilen yüksekliğe bir elektromıknatıs kullanılarak çıkarılır. Düşme yüksekliği programlanabilir mantık kontrolcüsünün arayüzünde yazılan programdan girilir. Düşen kütle iki adet kılavuz çubuk ile yataklanır. Bu yataklama çubukları düşen kütlenin piston dikey çarpmasını sağlar ve tüm hareket enerjisi bu şekilde piston aktarılmış olunur. Ayrıca kütlenin yataklanmış olması serbest düşme deneyini her ölçüm için bir önceki ile aynı şartlarda oluşturmasını sağlamaktadır ve bu sayede tekrarlanabilir ölçümler alınabilmektedir. 


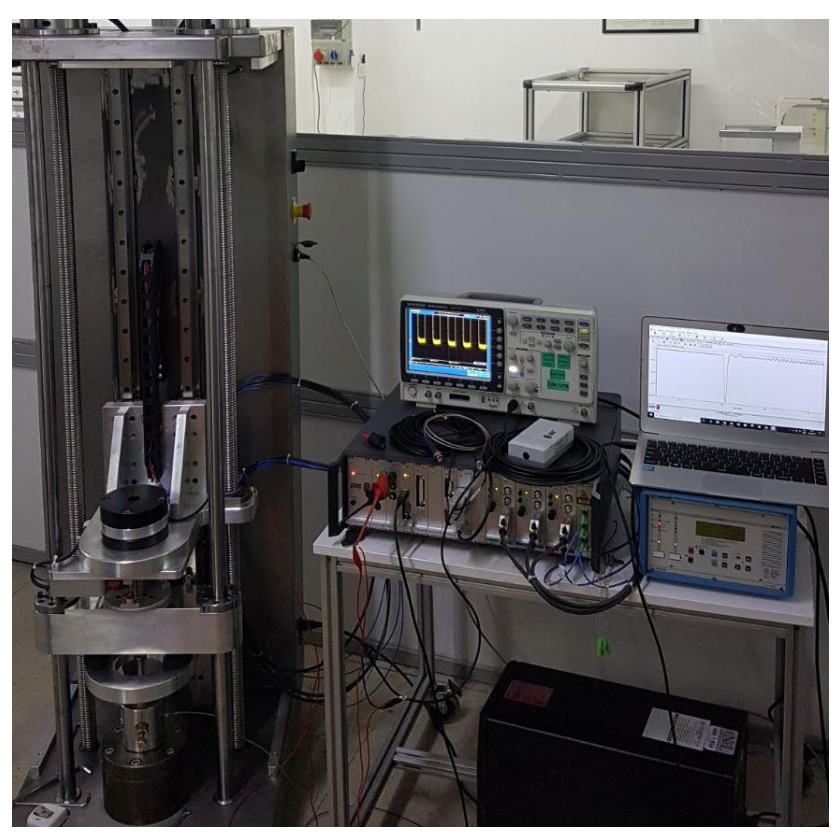

Şekil 2. Kütle düşürmeli dinamik basınç sistemi

Sistem kalibrasyon amacıyla kullanılmak üzere test basıncını, pistonun üzerine hızlıca düşen yataklanmış kütle ve pistonun da üzerine gelen bu etkiyi temas ettiği akışkana iletmesiyle üretir. Hidrolik akışkan içinde artan basınç birkaç yüz MPa değerine kadar ulaşmaktadır ve yüksek basınçlı dinamik test sensörlerinin hızlı ve doğru bir biçimde kalibre ve test edilmesini sağlar. Elde edilen enerji ve dolayısıyla basınç değeri, düşen kütlenin düşme yüksekliğinin değiştirilmesi ile değişmektedir ve ayarlanmaktadır.

Dinamik kalibrasyon sisteminde elde edilen referans basıç̧ (1) [4] numaralı formül ile hesaplanır:

$$
p=\frac{F}{A}
$$

p:Basınç [Pa], F:Kuvvet [N], A:Alan $\left[\mathrm{m}^{2}\right]$ değerlerini ifade etmektedir.

Formül (1)'deki ivme değeri, sistemde serbest düşmeye maruz kalan toplam kütlenin ivmesidir. Bu kütle grubu içinde, serbest düşen kütle, bu kütle ile beraber hareket eden piston kütlesi ve kapalı hacim içindeki yağın kütlesi vardır. Toplam kütle $\mathrm{m}_{\text {toplam }}$ olarak adlandırılmaktadır.

Buradan hareketler basınç (2) [5] numaralı formül ile daha detaylı ifade edilebilir:

$$
p \cong \frac{\left[m_{\text {toplam }} \cdot\left(m_{a, \text { maksimum }}+g\right)\right]}{A}
$$

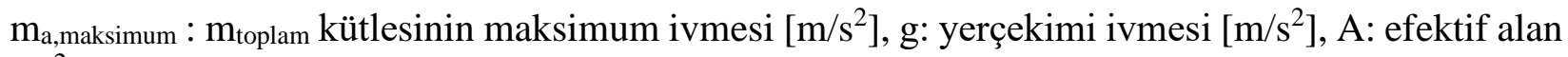
$\left[\mathrm{m}^{2}\right], \mathrm{m}_{\text {toplam }}:$ Hareket eden toplam kütle $(\mathrm{kg})$ değerlerini göstermektedir. 
Şekil 3'te dinamik sistem üzerine yerleştirilmiş olunan lazer interferometre sistemi görülmektedir. Makina üzerinde 2 farklı servo motor mevcuttur. Bir tanesi düşen kütleyi istenilen yüksekliğe çıkararak o noktadan serbest düşmeye bırakan elektromıknatısı hareket ettirirken diğer servo motor da düşen kütle pistona ilk defa çarptıktan sonra bozucu sinyal oluşturmasın diye kütlenin pistona tekrar çapmasını engelleyen tutucu sistemi hareket ettirmektedir. İlk motorun hareket ettirdiği elektromıknatıs kütleyi belli bir yüksekliğe çıkardıktan sonra kütle serbest düşmeye bırakılmaktadır. Kütlenin zamana karşı yer değiştirmesi lazer interferometrelerle ölçülmektedir. 3 adet lazer başlığı ve 3 adet lazer sinyal yansıtıcısı bu işlem için kullanılmaktadır. Yataklanan serbest düşen kütlenin $x-y$ ekseni etrafında oluşan dönme hareketi (pitch) ve dikey y ekseni etrafındaki dönme hareketi (yaw) etkileri, bu kütlenin ivme değerinin net olarak belirlenmesinde problemlere neden olabilmektedir. Bu etkilerin ortadan kaldırılması için 120'şer dereceyle kütle üzerine yerleştirilmiş 3 farklı lazer başlığı zamana karşı konum değişim bilgisini ölçmektedir. Toplam kütlenin ivmesi için 3 lazerden alınan ivme değerlerinin ortalaması kullanılmaktadır.

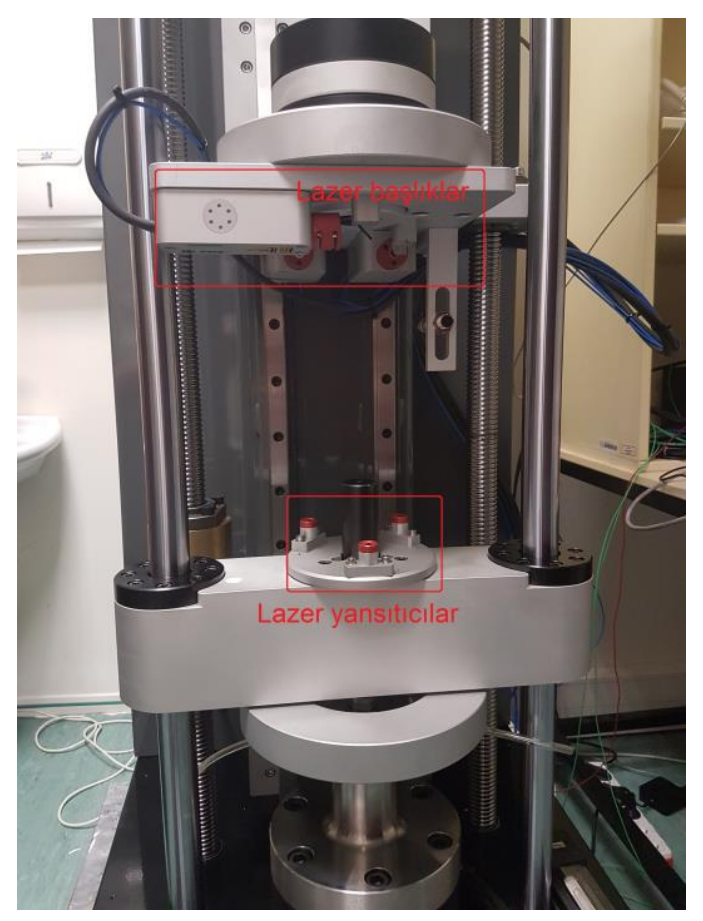

Şekil 3. Dinamik Kalibrasyon Sistemi Üzerindeki Lazer İnterferometre

Referans basıncın hesaplanması (1) ve (2) numaralı formüller ile açıklanmıştı. Bu formüllerde kullanılan piston-silindir ünitesinin efektif alan değerinin hesaplanması gereklidir. Bu hesaplama piston-silindir ünitesinin CMM cihazı adı verilen koordinat ölçüm makinesi yardımıyla boyutsal ölçümleri yapılmasıyla ve bu ölçülen boyutsal verilerinin analiz edilmesiyle hesaplanmaktadır. Piston-silindir ünitesinin boyutsal ölçümleri Şekil 4.'te verilmiştir. 

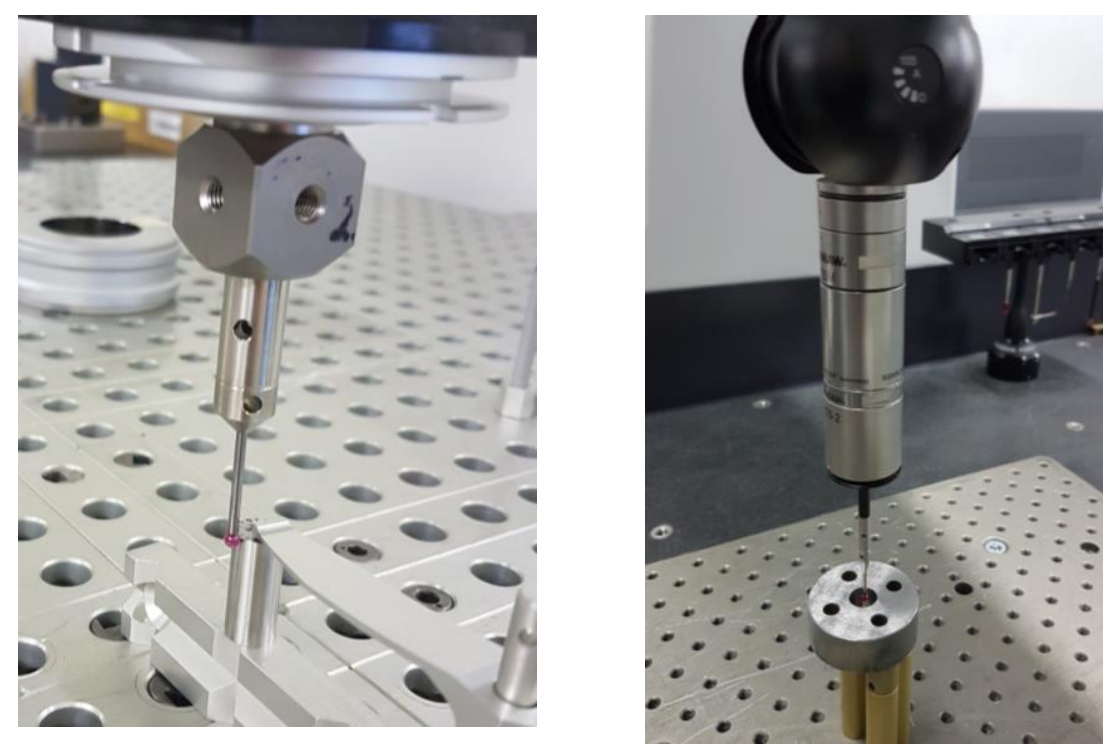

Şekil 4. Piston-silindir ünitesi boyutsal ölçümleri (soldan sağa doğru)

Piston silindir efektif alanını boyutsal yöntemler ile hesaplayabilmek için CMM cihazı ile her bir dairesel kesitte 45 derecelik aralıklarla X, Y ve Z koordinatları şeklinde 8 noktada veriler alınmıştır. Piston ve silindir yüksekliği $20 \mathrm{~mm}$ olup çalışma aralıği 15,5 mm olarak belirlenmiştir. 15,5 mm yükseklik boyunca her $0,1 \mathrm{~mm}$ 'de $8 \times 3=24 \mathrm{X}$, Y ve Z datas1 alınarak toplamda piston ve silindire ait 24x155=3720 veri elde edilmiştir. CMM cihazından alınan veriler excel programında derlenerek her bir kesit için ortalama yarıçap değerleri bulunmuştur. Yarıçap değerleri, sıfır basınçta boyutsal datalarla efektif alanı belirleyebilmek için kullanılan Dadson teorisindeki diğer parametrelerinde hesaplamasında kullanılmıştır. Denklemdeki integrallerin çözümü için sayısal integral hesaplama metotlarından Simpson's 3/8 kuralı kullanılmış ve çözüm sayısal integrasyon çözücü programında gerçekleştirilmişir.

\section{3. (50 - 400) MPa Aralığında Dinamik Sensör Kalibrasyonu}

Geliştirilen dinamik sistem ile, (50, 100, 200, 300, 400) MPa basınç değerlerinde piezoelektrik prensibine dayalı üretilmiş olunan Kistler marka bir dinamik basınç sensörünün ölçümleri gerçekleştirilmiştir. Referans basınç (2) numaralı formül yardımıyla hesaplanmıştır. Düşen toplamkütlenin ivme değerleri Tablo 1.'de ve bu ivme değerlerinin görünümü de Şekil 5.'te verilmiştir. 

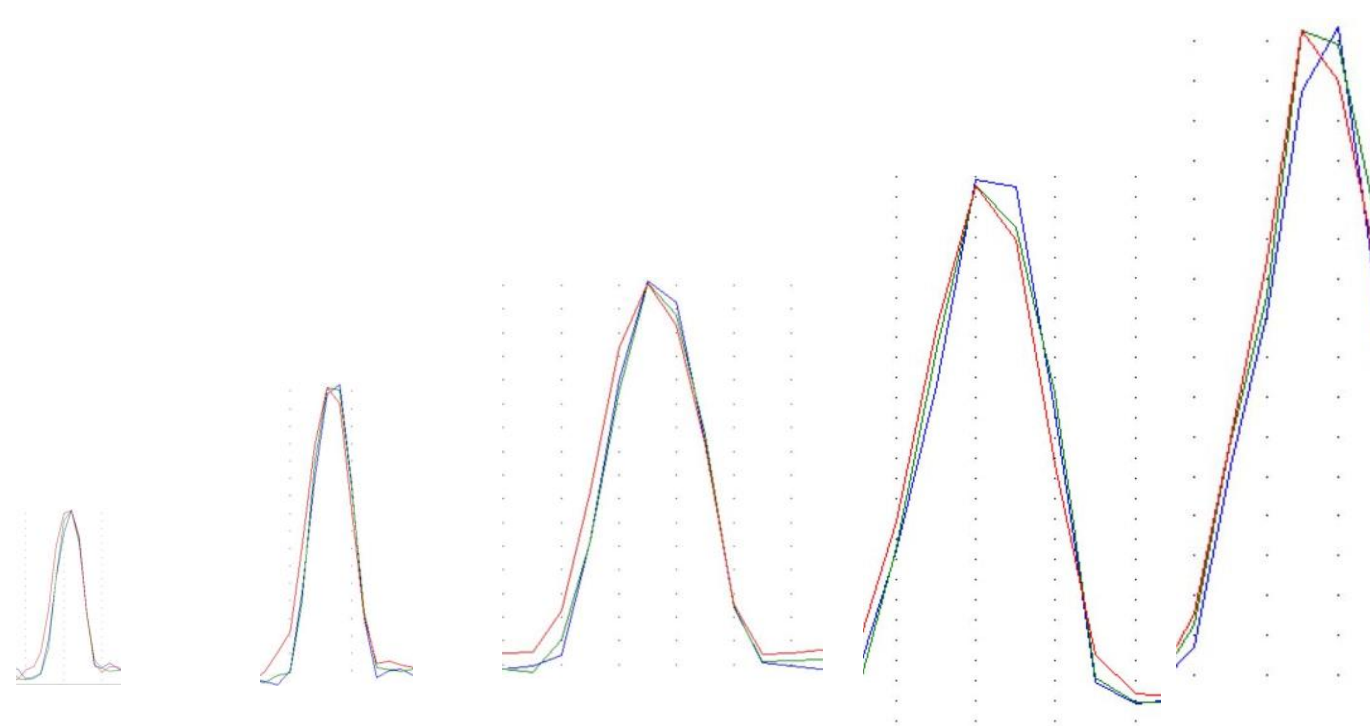

Şekil 5. Toplam kütle ivme değerleri (soldan sağa doğru $(50,100,200,300,400) \mathrm{MPa})$

Kalibrasyon sonuçları Tablo 1.'de verilmiştir. (50, 100, 200, 300, 400) MPa pnom nominal basınç değerlerini elde edecek şekilde, dinamik basınç sistemi kütlesi, ilgili tabloda görüldüğü üzere farklı yüksekliklerden serbest düşmeye bırakılmıştır. Her bir yükseklikten düşen kütlenin ivmesi ölçülerek referans basınç hesaplanmıştır. Test basıncı değerleri her bir darbeye karşı test sensörü tarafından oluşturularak fiber optik yük kablosu ile yükseltece gönderilmiş ve ptest test basıncı değerleri yükselteç ekranından okunmuştur. Hata değerleri, ptest-pref şeklinde hesaplanmaktadır.

Tablo 1. Kalibrasyon Sonuçları

\begin{tabular}{|c|c|c|c|c|c|c|c|c|c|c|c|}
\hline \multirow[b]{2}{*}{ p pom } & \multirow{2}{*}{$\begin{array}{l}\text { Düşme } \\
\text { Mesafesi }\end{array}$} & \multicolumn{5}{|c|}{$\mathrm{p}_{\text {test }}$} & \multicolumn{3}{|c|}{$\begin{array}{l}\text { Düşen toplam kütlenin } \\
\text { ivme değerleri }\end{array}$} & \multirow[b]{2}{*}{$\mathrm{p}_{\text {ref }}$} & \multirow{2}{*}{$\begin{array}{c}\text { p }_{\text {test }}-p_{\text {ref }} \\
\text { Hata }\end{array}$} \\
\hline & & $\# 1$ & $\# 2$ & $\# 3$ & $\# 4$ & $\# 5$ & $\begin{array}{c}\text { Laser } \\
\text { Başlık } \\
\# 1\end{array}$ & $\begin{array}{c}\text { Laser } \\
\text { Başl1k } \\
\# 2\end{array}$ & $\begin{array}{c}\text { Laser } \\
\text { Başl1k } \\
\# 3\end{array}$ & & \\
\hline MPa & $\mathrm{mm}$ & $\mathrm{MPa}$ & $\mathrm{MPa}$ & $\mathrm{MPa}$ & $\mathrm{MPa}$ & $\mathrm{MPa}$ & $\mathrm{m} / \mathrm{s}^{2}$ & $\mathrm{~m} / \mathrm{s}^{2}$ & $\mathrm{~m} / \mathrm{s}^{2}$ & $\mathrm{MPa}$ & $\mathrm{MPa}$ \\
\hline 50 & 5,5 & 49,5 & 50,5 & 50,0 & 50,5 & 50,0 & 431 & 430 & 383 & 56,2 & $-6,2$ \\
\hline 100 & 19,75 & 100,5 & 99,5 & 100,5 & 100,5 & 100,5 & 820 & 815 & 801 & 108,8 & $-8,3$ \\
\hline 200 & 85 & 200,0 & 200,0 & 200,0 & 200,0 & 200,5 & 1620 & 1658 & 1614 & 217,3 & $-17,3$ \\
\hline 300 & 230 & 298,5 & 300,0 & 300,0 & 298,5 & 300,0 & 2586 & 2566 & 2619 & 328,8 & $-28,8$ \\
\hline 400 & 430 & 3940 & 4060 & 4175 & 4290 & 4375 & 3276 & 3146 & 3137 & 4233 & -58 \\
\hline
\end{tabular}


Her serbest düşme ölçümü öncesi, kütle elektromıknatıs tarafından alınarak pistona doğru aşağıya indirilmektedir. Pistona dokunduğu anda gövde üzerine verilen zayıf akım elektrik devresi tamamlanmış olur. Elektrik devresinin tamamlanması etkisiyle PLC mıknatısı kontrol eden motorun hareketini durdurur. Sistem için serbest düşecek kütlenin piston dokunduğu bu nokta serbest düşme için referans sıfır noktası anlamına gelir. Atış yapılacak yükseklik sistem tarafından bu sıfır noktasından itibaren yukarı yönlü olarak ölçülür. Her seferinde ölçüm öncesi serbest düşecek kütle için referans sıfır noktasının tespiti, kütlenin hep aynı yükseklikten bırakılmasını sağlar ve bu durum da yapılan deneyin ölçüm sonuçlarının tekrarlanabilirliğinin iyileşmesine katkı sağlamaktadır.

\section{Sonuç}

Bu çalışmada, dinamik basınç sensörlerinin kalibrasyonlarının yapılması amacıyla primer düzeyde çalışması öngörülen dinamik basınç standardı geliştirilmesi amaçlanmıştır. Sistem tasarımı, temel elemanları ve çalışma prensibi anlatılmıştır. Örnek bir dinamik basınç sensörü seçilerek bu sensörün kalibrasyonu yeni geliştirilen sistemle yapılarak sonuçlar paylaşılmıştır. Yapılan ölçümlerde sistemin dinamik basınç sensörlerinin kalibrasyonları için kullanılabileceği görülmüştür.

İleriki çalışmalarda sistemin tekrarlanabilirliğinin arttırılmasına yönelik çalışmalar yapılması planlanmaktadır. Bu sayede daha hassas düzeyde ölçüm sonuçları elde edileceği düşünülmektedir.

$\mathrm{Bu}$ çalışma, EMPIR Avrupa Ortak Araştırma projeleri kapsamında Avrupa Birliği tarafından desteklenen «Dinamik Basınç ve Sıcaklıklar İçin Ölçüm ve Kalibrasyon Tekniklerinin Geliştirilmesi projesi (kısa adı: 17IND07 DynPT)» kapsamında yapılmıştır. EMPIR araştırma projeleri, Avrupa Birliği'nin Horizon 2020 araştırma ve inovasyon programı ve EMPIR katılımcı devletleri tarafından finanse edilmektedir.

\section{Kaynaklar}

[1] Uluslararası Metroloji Sözlüğü — Temel ve Genel Kavramlar, İlgili Terimler (VIM), TÜBİTAK UME C JCGM 2008.

[2] Bilgiç E., B. Durgut Y., Acta Phys. Pol. A, 128, B-267, (2015).

[3] Yasin Durgut, Eyup Bağc1, Ertan Akşahin \& Ahmet T. İnce, "An Investigation on Characterization of Dynamic Pressure Transducers Using Material Impact Test Machine", Journal of the Brazilian Society of Mechanical Sciences and Engineering (2017), pp 1-11, DOI: $10.1007 / \mathrm{s} 40430-017-0763-3$

[4] Guide to the Measurement of Pressure and Vacuum, The Institute of Measurement and Control, ISBN 090445729 X, 1998, London.

[5] Salminen J., Högström R., Saxholm S., Lakka A., Riski K., Heinonen M. Metrologia, 55, 52$59,(2018)$. 